\title{
JEZIKOVNA IZOBRAŽEVANJA ZA ODRASLE PRISELJENCE NA PRIMERU FRANCOSKEGA NEVLADNEGA SEKTORJA
}

\section{POVZETEK}

$V$ članku je predstavljena praksa jezikovnih izobraževanj za odrasle priseljence v Franciji. Avtorica se osredotoča na nevladni sektor v pariški regiji, ki se pogosto opira na metodo sociolingvističnih delavnic. Slednja poskuša hitro in učinkovito odgovoriti na komunikativne in socialne potrebe priseljencev $v$ novem okolju. Obstaja še vrsta drugih načinov in pristopov poučevanja francoščine, kot je na primer »sprejemna delavnica «ruštva Atouts Cours, ki jo predstavlja avtorica ter dodaja nekaj strokovnih in izkustvenih spoznanj. Zaključi z razmislekom o možnih aplikacijah svojih ugotovitev v slovensko prakso.

Ključne besede: integracija priseljencev, Francija, jezikovna izobraževanja, metoda sociolingvističnih delavnic, nevladni sektor

\section{LANGUAGE COURSES FOR ADULT IMMIGRANTS: THE EXAMPLE OF THE FRENCH NON-GOVERNMENTAL SECTOR - ABSTRACT}

The article presents the practice of language courses for adult immigrants in France. The author focuses on the non-governmental sector in the Paris area, which is often based on the method of sociolinguistic workshops. This method tries to respond quickly and efficiently to the communication and social needs of immigrants in the new environment. There is a whole variety of other ways and approaches of teaching French, for example "reception workshops" in the association Atouts Cours. The author presents this workshop and some professional and empirical findings. In the last part, she adds a reflection on the possible applications of her findings in the Slovenian practice.

Keywords: integration of immigrants, France, language courses, sociolinguistic workshop method, non-governmental sector 
Razprave o migracijski politiki in integraciji priseljencev so aktualne tako v Sloveniji kot Evropi. Sestavni del integracije priseljenca v novo državo je tudi učenje jezika države gostiteljice oziroma novega okolja. Tega vprašanja se države gostiteljice različno lotevajo. V prispevku želim predstaviti nekaj izkustvenih in strokovnih spoznanj o jezikovnih izobraževanjih za odrasle priseljence v Franciji, ki sem jih kot pripravnica praktičnega usposabljanja Erasmus+ pridobila med štirimesečnim delom v društvu Atouts Cours v Parizu. Pridobljena spoznanja bom nato poskušala povezati s slovensko prakso in izluščiti ugotovitve, ki lahko prinesejo nove poglede na to področje v Sloveniji.

\section{VLOGA JEZIKA PRI INTEGRACIJI V NOVO DRŽAVO}

Ko priseljenec stopi na ozemlje tuje države, je eden izmed njegovih glavnih ciljev, da se čim hitreje nauči jezika, da se bo v novem okolju lahko sporazumeval (Adami, 2009). To pomeni, da jezik države gostiteljice za priseljenca pomeni potrebo, saj ga potrebuje za življenje. Jezik države gostiteljice tako ni svobodna izbira niti cilj sam po sebi, ampak sredstvo (prav tam) - sredstvo, ki omogoča življenje v državi gostiteljici in sredstvo integracije (Adami, 2008, str. 13). Ob tem pa ima jezik države gostiteljice oziroma dominantni jezik okolja v procesu integracije priseljenca več vlog (Adami, 2012b). Instrumentalna vloga pomeni, da je jezik nepogrešljiv pripomoček v vsakdanjem življenju priseljenca, simbolična vloga omogoča integracijo v skupnost, s političnega vidika pa je znanje jezika pogoj za naturalizacijo. Učenje jezika države gostiteljice je torej za priseljenca obvezno in tudi nujno, saj mu šele jezik omogoča sodelovanje v lokalni skupnosti, zaposlitev, izobraževanje, spremljanje šolanja otrok itd. (Donnard, 2009).

\section{JEZIKOVNA IZOBRAŽEVANJA ZA PRISELJENCE V SLOVENIJI}

Preden predstavimo francosko prakso, na kratko preglejmo izobraževalne možnosti, ki jih imajo priseljenci v Sloveniji. V povezavi s poučevanjem slovenščine za priseljence v Sloveniji največkrat govorimo o slovenščini za tujce ter o slovenščini kot drugem in tujem jeziku. Ponudnikov takih izobraževanj je več. Osrednji akter na tem področju je Center za slovenščino kot drugi in tuji jezik, ki med drugim skrbi za poučevanje slovenščine, pripravo učnih gradiv in raziskovanje tega področja (CSDTJ, b. d.). Po državnem programu, imenovanem Začetna integracija priseljencev - ZIP, brezplačne programe učenja slovenščine izvaja še nekaj drugih organizacij, na primer Javni zavod Cene Štupar in Andragoški zavod - Ljudska univerza Maribor (Info tujci, b. d.). Poleg teh se lahko priseljenci slovenščino učijo še $\mathrm{v}$ zasebnih jezikovnih šolah in tudi pri nekaterih nevladnih organizacijah (Slovenska filantropija, Društvo za razvijanje prostovoljnega dela Novo mesto idr.). V Sloveniji za poučevanje slovenščine obstaja tudi javnoveljavni program Slovenščina kot drugi in tuji jezik, v okviru katerega so predpisani trajanje programa, standardi znanja, vsebine programa, gradivo, preverjanje znanja itd. (Slovenščina kot drugi in tuji jezik, 2014). 


\section{JEZIKOVNA IZOBRAŽEVANJA ZA PRISELJENCE V FRANCIJI}

Tudi v Franciji imajo razvejeno mrežo izobraževalnih organizacij, ki ponujajo različne programe za učenje francoščine. Nekatere so imetnice državnega certifikata za izvajanje jezikovnih izobraževanj za odrasle priseljence z oznako FLI (Français langue d'intégration) - francoščina kot jezik integracije (Francosko ministrstvo za notranje zadeve, 2016), veliko pa jih prihaja iz nevladnega sektorja, ki tudi razvija teorijo in prakso poučevanja francoščine za odrasle migrante. Njihova didaktična spoznanja in gradiva so pomembna, saj je, kot pravi Adami (2010-2011), to področje didaktike strokovno razmeroma neraziskano in zapostavljeno. V pariški regiji tako poznamo društva CEFIL, ${ }^{1}$ Le RADyA $^{2}$ in Réseau Alpha. ${ }^{3}$ Med njihovimi izobraževalnimi dejavnostmi so tečaji opismenjevanja, pouk francoščine kot tujega jezika, delavnice usvajanja temeljnega znanja, jezikovno izobraževanje za poklicno rabo, sociolingvistične delavnice in tečaji za pridobivanje diplome DILF (Fédération des centres sociaux et socioculturels de Paris, b. d.). Nekatera društva pa imajo še inovativnejšo ponudbo izobraževalnih dejavnosti, na primer delavnice glasnega branja v francoščini pri društvu FISPE (2016) ali umetniške delavnice pri društvu Atouts Cours (b. d.).

Če bi želeli poiskati skupni imenovalec vseh naštetih izobraževanj, bi jih lahko poimenovali z izrazom raziskovalca Adamija (2012a) »jezikovno izobraževanje za odrasle migrante « (fr. formation linguistique des migrants adultes - FLMA). S tem izrazom jih tudi ločimo od poučevanja francoščine $\mathrm{v}$ osnovnih in srednjih šolah, za kar se uporablja izraz »francoščina kot drugi jezik « (Cuq ur., 2003, str. 108-109). Raznolika ponudba jezikovnih izobraževanj, ki smo jo opisali, poskuša francoščino na različne načine približati priseljencem. Ob tem so različni načini poučevanja primerni za različne ciljne skupine. Prilagajanje ciljnim skupinam pa pomeni prilaganje njihovim potrebam, kar je ključnega pomena za uspešen učni proces. Priseljenci v Francijo prihajajo z različnimi pričakovanji in cilji, ob tem pa bi moralo biti zagotovljeno, da imajo vsi pravico in dostop do učenja francoščine. Pomembno je, da izobraževanja poskušajo narediti jezik države gostiteljice za priseljence smiseln in uporaben, zato naj bo glavni cilj teh izobraževanj poučevanje jezika za uporabo v vsakdanjem življenju. Primer za tako izobraževanje bomo spoznali v nadaljevanju.

\section{METODA SOCIOLINGVISTIČNIH DELAVNIC}

Da bi bilo pridobljeno znanje jezika in tudi znanje o kulturi države gostiteljice čim prej uporabno v vsakdanjem življenju priseljencev, so M. De Ferrari, B. Forzy in M. Nguyên

1 Centre d'études, de formation et d'insertion par la langue (Center raziskovanja, izobraževanja in vključevanja prek jezika). Več na: http://cefil.org/.

2 Réseau des Acteurs de la Dynamique ASL (Mreža akterjev dinamike ASL). Več na: http://www.aslweb. fr/radya-menu/.

3 Réseau Alpha - Le site collaboratif de l'apprentissage du français en Île-de-France (spletna stran za sodelovanje na področju učenja francoščine v regiji Île-de-France). Več na: http://www.reseau-alpha.org/nos-actions. 
(2004) zasnovale posebno metodo poučevanja francoščine za priseljence, poimenovano sociolingvistične delavnice (fr. les ateliers sociolinguistiques $-A S L$ ). Ta metoda se največ uporablja v nevladnem sektorju pariške regije. V nadaljevanju jo opisujemo na podlagi njihovega dela (prav tam). Metoda sociolingvističnih delavnic je didaktični način s ciljem, da priseljenci s pomočjo komunikacije $v$ francoščini čim hitreje postanejo dejavni družbeni akterji v svojem okolju. Usmerjena je v pridobivanje komunikacijskih in socialnih kompetenc z namenom, da bi lahko priseljenci samostojno nastopali in komunicirali v javnih službah in družbenih prostorih (na primer zdravstvenem domu, uradih, pošti, centru za socialno delo). Hkrati s tem poteka tudi učenje vrednot in načel francoske družbe in republike. Delavnice po tej metodi se izvajajo v tematskih sklopih, ki zadevajo javni, kulturni, osebni in državljanski vidik življenja priseljenca (na primer administracija, laičnost, zdravje, zaposlitev). Metoda je usmerjena v razvoj osmih kompetenc, med katerimi niso le jezikovne in komunikacijske, ampak tudi zmožnost delovanja $\mathrm{v}$ javnem prostoru (na primer naročiti se na pregled pri zdravniku), zmožnost delovanja v skladu z družbenimi normami (na primer pravilno vikati in tikati), zmožnost uporabe interneta in avtomatov in drugo (Co-Alternatives, 2014). Izobraževanje je torej praktično naravnano, saj cilja na to, da se priseljenci čim bolje spoznajo z okoljem in bodo lahko v njem živeli in komunicirali. Ni pa opisana metoda primerna za vse priseljence, saj ponuja učenje osnovnih vzorcev delovanja na uradih in podobno, kar je potrebno predvsem za priseljence, ki prihajajo iz držav v razvoju in držav, ki so manj administrativno urejene, oziroma za tiste priseljence, ki so manj izobraženi.

\section{DELOVANIE DRUŠTVA ATOUTS COURS V PARIZU}

Nevladni sektor, ki pokriva jezikovna izobraževanja za priseljence v Franciji, ima pogosto cilj, da priseljence čim prej opremi s potrebnim znanjem jezika in kulture za vsakdanje življenje. Tudi v društvu Atouts Cours je tako, saj je njihovo osnovno poslanstvo poučevanje francoščine za priseljence s ciljem integracije skozi učenje jezika (Atouts Cours, b. d.). Dejavnosti, ki jih društvo ponuja za priseljence, so tečaj opismenjevanja (začetna in nadaljevalna stopnja), tečaj francoščine kot tujega jezika (več stopenj), kulturne dejavnosti (muzej, glasba ...) in dejavnost javnih pisarjev (pomoč pri pisanju uradnih besedil in administrativnih dokumentov) (prav tam). Društvo ima prostore v 18. pariškem okrožju v večkulturni četrti, kjer je po njihovih podatkih velik delež prebivalcev priseljenih, večinoma iz Magreba in drugih afriških držav. Veliko teh prebivalcev četrti je tudi njihovih uporabnikov. $\mathrm{V}$ času mojega usposabljanja je bilo v društvu zaposlenih pet oseb. Na čelu društva je bil direktor, poleg njega pa vodja projektov. Za sprejem in svetovanje novim uporabnikom je skrbela kulturna mediatorka. Slednja je najprej testirala njihovo predznanje jezika, potem pa jih je razporedila na ustrezen tečaj ali dejavnost. Za pedagoški proces je bila pristojna pedagoška koordinatorica, ki je zagotavljala podporo izvajalcem tečajev in skrbela za didaktična gradiva. Poleg nje je deloval tudi koordinator prostovoljcev, ki je z organizacijskega vidika skrbel za nemoteno izvajanje dejavnosti. Po podatkih njihove spletne strani (Atouts Cours, b. d.) v društvu tedensko opravijo več 
kot sto delavnic. Izvajalci teh delavnic so večinoma prostovoljci, ki pa pogosto nimajo pedagoške ali andragoške izobrazbe. Društvo se drži načela, da se lahko uporabniki v tečaje vključijo ali jih opustijo v kateremkoli času v letu, čeprav v okviru pedagoškega leta dejavnosti potekajo nepretrgoma. To omogoča novoprispelim priseljencem, da se lahko takoj vključijo v izobraževalni proces in jim ni treba čakati novega leta. Pomanjkljivost pa je, da se dinamika skupine in ritem učenja ves čas spreminjata, kar izvajalcu tečaja otežuje delo in zmanjšuje učinkovitost učenja.

Za priseljence, ki nimajo nič ali zelo malo predznanja francoščine, je društvo Atouts Cours razvilo poseben tečaj, ki mu pravijo »sprejemna delavnica« oziroma »l'atelier d'accueil«. Pri predstavitvi te delavnice bom izhajala iz ugotovitev svojega magistrskega dela (Gorenc, 2017). Sprejemna delavnica je intenzivni tečaj (24 učnih ur v treh tednih), katerega cilj je, da udeleženci ob uporabi francoščine čim hitreje vstopijo v interakcijo z ljudmi in se tako vključijo v francosko družbo. Namenjena je priseljencem, ki v Francijo pridejo brez predznanja francoščine, na njej pa se naučijo nekaj osnov francoskega jezika in kulture. V skupinah sprejemne delavnice, kot sem jih spoznala sama, je bilo od 15 do 20 udeležencev. Večina je prihajala iz afriških držav (Somalija, Sudan, Nigerija, Maroko, Egipt), azijskih (Šrilanka, Bangladeš, Pakistan) in tudi evropskih (Madžarska, Poljska, Portugalska). To so bili na novo priseljeni tujci ali pa osebe, ki se med daljšim bivanjem v Franciji še niso vključile $\mathrm{v}$ francosko govorečo družbo in tako niso bile $\mathrm{v}$ stiku z jezikom. Osnovni cilji so komunikacijski, torej da se udeleženci naučijo osnovne ustne komunikacije v vsakdanjem življenju, kamor sodijo tudi temeljne sociolingvistične kompetence (uporaba vikanja, vljudnostnih fraz, primernega registra ...). Vsebina delavnice je tako razdeljena na štiri dele: (1) lastna identiteta (kako se predstaviti), (2) kontakt z okolico (kako sodelovati v preprostem pogovoru), (3) neposredna okolica (poznati mesto, transportna sredstva ...) in (4) vsakdanje življenje (trgovina, zdravnik, banka ...). Priseljenci na tej stopnji osvojijo še znanja o nekaterih družbenokulturnih značilnostih francoske družbe in države, na primer spoznajo državne institucije, laičnost kot republikansko načelo, praznike, navade.

\section{MOIA IZKUŠNJA IN SPOZNANIA}

Med praktičnim usposabljanjem sem bila $v$ društvu pristojna za izvajanje rednih delavnic opismenjevanja in poučevanja francoščine v različnih skupinah in tečajih. Poleg tega sem skrbela za knjižnico in sodelovala pri raziskovalni dejavnosti pedagoške koordinatorice. Nadgradila in pripravila sem nekaj didaktičnega gradiva in didaktičnih priročnikov za prostovoljce, najbolj pa sem se posvetila teoriji in praksi opismenjevanja in sprejemne delavnice. Pri delu mi je za eno izmed izhodišč služila metoda sociolinvističnih delavnic. Pomembna mi je bila tudi uporaba avtentičnih dokumentov, saj ti v izobraževalni prostor prinašajo dimenzijo vsakdanjega življenja, s čimer povečajo avtonomijo in motivacijo učečih se (Bérard, 1991). Naslednje pomembno izhodišče so mi bile potrebe udeležencev izobraževanja. Potrebe iz vsakdanjega življenja priseljencev (na primer vpisati otroka $\mathrm{v}$ šolo) sem prevedla $\mathrm{v}$ jezikovne potrebe (izpolniti vpisni list, 
govoriti z učiteljem ...) in druga potrebna znanja (na primer poznati šolski red). Te potrebe lahko v nadaljevanju prevedemo še v učne cilje in ciljne kompetence, ki jih želimo doseči v posamezni učni enoti (Gorenc, 2017). Na ta način sem načrtovala učni proces, ki mora torej vedno izhajati iz potreb udeležencev, kar razlagata tudi Van Avermaet in Gysen (2008).

Zadovoljiti pričakovanja in potrebe vsakega udeleženca ter mu ponuditi ustrezno izobraževanje oziroma vsebino je eden glavnih izzivov, ki sem jih zaznala pri svojem delu. Adami (2005) in Donnard (2009) namreč ugotavljata, da so udeleženci jezikovnih izobraževanj v Franciji različno stari, imajo različno stopnjo izobrazbe in različne potrebe. Poleg tega imajo tudi različne motivacije in pričakovanja (Fédération des centres sociaux et socioculturels de Paris, b. d.). Zaradi te raznolikosti udeležencev je učni proces težko načrtovati in tudi izvesti. S to težavo se verjetno sooča vsak izobraževalec $\mathrm{v}$ tem procesu. Tudi sama sem se v sprejemni delavnici znašla v skupini priseljencev, starih od 25 do 50 let, z različno stopnjo izobrazbe, od profesorjev do nepismenih oseb. Iz tega razloga je za vsako organizacijo, ki se ukvarja z izobraževanji za priseljence, izjemno pomembno, da razčleni ponudbo dejavnosti po različnih ciljnih skupinah ter zagotovi delo v majhnih in čim bolj homogenih skupinah. V društvu Atouts Cours so to poskušali reševati s testom predznanja pred vključitvijo v izobraževanje. Test je udeležence razločeval po stopnji predznanja francoščine, ne pa tudi po drugih značilnostih, zaradi česar so bile skupine še vedno zelo heterogene.

Ena izmed pomanjkljivosti nevladnega sektorja, kot sem ga spoznala sama, je, da lahko večino pedagoškega dela opravijo prostovoljci, ki niso nujno usposobljeni za to delo. Izbira izobraževalca za neko skupino je tako lahko naključna. Poleg tega pa je težko imeti pregled nad delom posameznega prostovoljca, zato se lahko način in kakovost poučevanja od prostovoljca do prostovoljca zelo razlikujeta. Za primer povejmo, da se pri obravnavi slovnice prostovoljci pogosto opirajo na uporabo metajezika, ki pa za potrebe vsakdanje komunikacije priseljencev ni potrebna in lahko celo otežuje proces učenja pri tistih z manj jezikoslovnega predznanja. Pri poučevanju pa je treba upoštevati tudi predstave udeležencev o »pravem « učenju, saj bi nekateri jezik raje obravnavali sistematično z veliko pravili in vajami (De Ferrari, b. d.), medtem ko bi drugim bolj ustrezalo več uporabe v vsakdanjih primerih. Nevladni sektor si mora torej prizadevati za to, da ponuja kakovostno izobraževanje za svoje uporabnike, pri tem pa skrbeti za strokovna izobraževanja svojih prostovoljcev. Tudi v Sloveniji je še veliko prostora za razvoj izobraževanj za prostovoljce, ki poučujejo priseljensko populacijo. Kar pa se tiče državnih programov za tujce, v Sloveniji obstajata dva pravilnika, ki določata strokovno izobrazbo učiteljev v izobraževalnem programu za odrasle Slovenščina kot drugi in tuji jezik in v programu Slovenščina za tujce (MIZS, 2017).

Čeprav prispevek ne obravnava dela slovenskih nevladnih organizacij na področju jezikovnih izobraževanj za priseljence, ga bomo sklenili z nekaj predlogi za to področje na Slovenskem. Glavna smernica za oblikovanje jezikovnih izobraževanj za priseljence je, da se mora ponudba izobraževalnih programov vedno prilagajati jezikovnim potrebam 
posameznih skupin priseljencev. Tako je smiselno uporabnike izobraževanj ločevati po starosti, izobrazbi, socialnem in kulturnem poreklu ... Tudi spol lahko včasih določa potrebe učeče se osebe. Na primer priseljenke iz nekaterih okolij so pogosto bolj vpete $\mathrm{v}$ varstvo in šolanje svojih otrok kot moški, zaradi česar potrebujejo znanja, ki se nanašajo na te teme. S tega vidika je možnosti za razvoj različnih specifičnih izobraževalnih programov veliko. Tudi na področju učenja slovenščine za poklicno rabo je možno ponuditi izobraževanja za različna delovna področja in poklice. V Sloveniji je možna tudi aplikacija metode sociolingvistične delavnice, za kar bi bile potrebne nekatere prilagoditve glede na stopnjo predznanja učečih se. Tudi sprejemna delavnica bi lahko v Sloveniji postala smiselna, še posebno ob večjih migracijskih valovih, kjer bi morali priseljencem v kratkem času predati vsaj temeljna znanja slovenskega jezika in kulture. Dobro je tudi, da bi taka izobraževanja imeli pripravljena že vnaprej.

Za boljše poznavanje izobraževalnih možnosti za priseljence v Sloveniji kot tudi za prepoznavanje potreb po teh izobraževanjih je potrebno nadaljnje poglobljeno raziskovanje tega področja. In čeprav smo videli nekaj pomanjkljivosti, ki se lahko pojavijo v nevladnem sektorju, ta pomeni velik potencial za razvoj jezikovnih izobraževanj za priseljence tudi v Sloveniji. Treba pa je zagotoviti kakovostna izobraževanja, usposobljene prostovoljce in program, ki bo po vsebini in metodi ustrezal potrebam priseljencev. Ker pa navadno vsebine takih programov vključujejo veliko kulturnih in družbenih prvin, bi jih lahko poimenovali tudi družbenojezikovne oziroma sociolingvistične.

\section{LITERATURA}

Adami, H. (2005). Les faux jumeaux didactiques. Le français dans le monde, 339, 23-26.

Adami, H. (2008). L'accuturation linguistique des migrants : des tactiques d'apprentissage à une sociodidactique du français langue seconde. Cahiers de l'Observatoire des pratiques linguistiques, 2, 10-15. Pridobljeno s http://www.culturecommunication.gouv.fr/Ressources/Publications/Cahiersde-1-Observatoire-des-pratiques-linguistiques-n-2-migrations-et-plurilinguisme-en-France.

Adami, H. (2009). Les documents authentiques dans la formation des adultes migrants : pratiques pédagogiques et contraintes institutionnelles. Mélanges CRAPEL, 31, 159-172. Pridobljeno s http://www. atilf.fr/IMG/pdf/melanges/09_Adami.pdf.

Adami, H. (2010-2011). Intégration et formation linguistiques des migrants adultes. Culture et recherche, 124, 17. Pridobljeno s http://www.culture.gouv.fr/culture/editions/documents/cr124_p17.pdf.

Adami, H. (2012a). La formation linguistique des migrants adultes. Savoirs, 2(29), 9-44.

Adami, H. (2012b). L'intégration et la formation linguistiques des migrants : politiques et pratiques en France. Pridobljeno s http://www.unige.ch/fapse/rift/files/8414/1571/8108/H_Adami_Presentation_01_11_12.pdf .

Atouts Cours. (b. d.). Pridobljeno s http://atoutscours.org/association/.

Bérard, E. (1991). L'approche communicative : théorie et pratiques. Paris: CLE International.

Co-Alternatives. (2014). Axes de compétences ASL. Pridobljeno s http://co-alternatives.fr/wp-content/ uploads/2014/05/ASL-axes-competences-2014.pdf.

CSDTJ. (b. d.). Pridobljeno s http://centerslo.si/.

Cuq, J. (ur.). (2003). Dictionnaire de didactique du français langue étrangère et seconde. Paris: CLE International. 
De Ferrari, M. (b. d.). Penser la formation linguistique des adultes migrants en France : Nommer autrement pour faire différemment. Pridobljeno s http://crpve91.fr/Politique_de_la_Ville/Cohesion_sociale/Productions_du_CRPVE/7_avril_2011/Deferrari-penser-formation-autrement-LFDM-juillet-2008.pdf.

De Ferrari, M., Forzy, B. in Nguyên, M. (2004). Guide descriptif-Actions socialisantes à composante langagière. Pridobljeno s http://www.cri-aquitaine.org/fileadmin/user_upload/mediatheque/Actions_de_formations/ASL/Guide_ASL_CLP.pdf.

Donnard, G. (2009). Formation linguistique : un nouvel enjeu des politiques d'intégration?. Pridobljeno s http://www.oriv-alsace.org/wp-content/uploads/oriv_cahier_observatoire_quarante_trois.pdf.

Fédération des centres sociaux et socioculturels de Paris. (b. d.). Repères pour les actions linguistiques en centre social - pistes de travail pour les coordinateurs et les formateurs. Pridobljeno s http:// www.centres-sociaux.fr/files/2010/07/Rep\%C3\%A8res-pour-les-actions-linguistiques-en-centre-soial.pdf.

FISPE. (2016). Pridobljeno s http://www.fispe.fr/.

Francosko ministrstvo za notranje zadeve. (2016). Pridobljeno s http://www.immigration.interieur.gouv. $\mathrm{fr} /$ Accueil-et-accompagnement/La-nationalite-francaise/Les-organismes-de-certification.

Gorenc, V. (2017). Enseignement du français aux migrants adultes en France : Objectifs d'apprentissage et approches didactiques (Magistrsko delo). Filozofska fakulteta, Ljubljana.

Info tujci. (b. d.). Pridobljeno s http://www.infotujci.si/s/2/te\%C4\%8Daji-slovenskega-jezika.

MIZS. (2017). Pridobljeno s http://www.mizs.gov.si/si/delovna_podrocja/direktorat_za_srednje_in_visje_solstvo_ter_izobrazevanje_odraslih/izobrazevanje_odraslih/izobrazevalni_programi_za_odrasle/ posebni_programi_za_odrasle/\#c17651.

Slovenščina kot drugi in tuji jezik. (2014). Pridobljeno s http://arhiv.acs.si/programoteka/Slovenscina_ kot_drugi_in_tuji_jezik.pdf.

Van Avermaet, P. in Gysen, S. (2008). Apprentissage, enseignement et évaluation des langues, et intégration des migrants adultes. Importance de l'analyse des besoins. Seminar L'intégration linguistique des migrants adultes (str. 63-75). Strasbourg: Svet Evrope. Pridobljeno s https://www.coe.int/t/dg4/ linguistic/Migr_ThematicStudies08_FR.pdf. 